\title{
WILHELM MICHLER, UMA AVENTURA CIENTÍFICA NOS TRÓPICOS
}

\author{
Nadja Paraense dos Santos, Angelo C. Pinto e Ricardo Bicca de Alencastro
}

Departamento de Química Orgânica - Instituto de Química - Universidade Federal do Rio de Janeiro - Cidade Universitária 21945-970 - Rio de Janeiro - RJ

Recebido em 25/3/99; aceito em 16/12/99

\begin{abstract}
WILHELM MICHLER, A SCIENTIFICAL ADVENTURE IN THE TROPICS. Wilhelm Michler lived in Brazil for seven years from 1882 to 1889 , when he died. Here, he published several articles on natural products, and became a professor of Industrial Chemistry at the Escola Politécnica, in Rio de Janeiro. He was respected by colleagues and students. This article addresses this poorly known period of the life of a scientist, world-famous by the aromatic ketone that carries his name.
\end{abstract}

Keywords: Michler; history of chemistry; chemistry teaching; Escola Politécnica.

\section{INTRODUÇÃO}

Uma observação que ressalta claramente da análise das condições educacionais do Brasil e de Portugal entre os séculos XVI e XIX é a defasagem temporal em relação aos países onde a ciência se desenvolveu. Dentre os fatores que limitaram o desenvolvimento das ciências no Brasil podemos destacar a baixa qualidade da ciência portuguesa, a política de imperialismo cultural nos séculos XVII e XVIII, e a falta de um rompimento decisivo com as tradições coloniais na época da independência ${ }^{1}$.

Somente em 1772, o marquês de Pombal, Sebastião José de Carvalho e Melo (1699-1782), principal ministro do rei D. José I (1715-1777), pode dar partida a seu projeto político de transformar Portugal em uma nação moderna, com a reforma drástica do ensino superior do país, muito atrasado em relação aos padrões dos demais países europeus. Pela reforma de Pombal, a Universidade de Coimbra (criada em 1290) passou a voltarse principalmente para a ciência aplicada, em contraste com o ensino escolástico até então dominante.

O "ensino das novas ciências exigia", paralelamente, "uma nova metodologia" de abordagem da natureza, realizada em "estabelecimentos novos", tais como um horto botânico, um laboratório de química e de física, um dispensário farmacêutico ${ }^{* 1}$ e um laboratório de anatomia ${ }^{2}$. O "Laboratório Químico" foi concluído no início de 1776 e serviu de sede ao Departamento de Química da Universidade de Coimbra por quase duzentos anos. Embora tivessem aparecido no país algumas instituições dedicadas à química no decurso do século XIX, o Laboratório Químico da Universidade de Coimbra foi o único de nível universitário em Portugal até a criação das Universidades de Lisboa e do Porto, em 1911. Foi, portanto, com a reforma de Pombal que a química ingressou no ensino superior em Portugal para abrir as oportunidades de utilização e industrialização de produtos naturais e colocar Portugal na senda do desenvolvimento industrial que a Europa então trilhava. É fácil perceber que os idealizadores da política ilustrada reformista incentivavam a produção agrícola e a exploração mineral nas colônias, ao mesmo tempo em que prescreviam para a metrópole uma política manufatureira e de reformas ${ }^{3}$.

De conformidade com o interesse mercantilista de Portugal em novas matérias primas, muitos esforços foram feitos até o

nadja@iq.ufrj.br; angelo@iq.ufrj.br; bicca@iq.ufrj.br

${ }^{*}$ Dispensários farmacêuticos eram laboratórios que funcionavam junto às faculdades de farmácia e medicina para demonstrações práticas de preparação de medicamentos. século XVIII no reconhecimento e coleta de novos produtos com possível valor comercial. Por orientação do Governo Central, as autoridades coloniais faziam reunir, de forma mais ou menos sistemática, espécimes de plantas e animais que eram enviados a Portugal e, eventualmente, tentativas organizadas de aclimatação nas colônias de espécies economicamente promissoras foram feitas. As disputas de fronteiras no Brasil colonial, por outro lado, criaram a necessidade de mapas precisos, que estimularam trabalhos topográficos e cartográficos de qualidade pelos engenheiros militares, forçando, assim, a criação dos primeiros cursos de alto nível no País.

Apesar da reforma educacional de Pombal não ter sido levada até ao fim, o interesse pelo cultivo da química na fase inicial é manifesto. Como acontecimento marcante da época podemos registrar, o aparecimento, em 1788, dos "Elementos de Chymica", de Vicente Coelho de Seabra Silva Telles ${ }^{4,5}$. A segunda parte da obra, mais completa, publicada em 1790, já utilizava a linguagem da nova nomenclatura de Lavoisier, apesar de ter sido escrita um ano depois da publicação do "Traité Elémentaire de Chimie", obra culminar na revolução da química que então se iniciava.

No Brasil do começo do século XIX quase nada havia em termos de ensino ou trabalhos científicos. A chegada da Família Real Portuguesa e a conseqüente transformação da colônia em sede do governo, com transferência de pessoal e material, facilitou a instalação de cursos superiores que contemplavam o estudo das ciências naturais ${ }^{6}$. Assim "teve início a história institucional da ciência no país", seguindo "modelos tradicionalmente reconhecidos" na Europa e "vistos pela Coroa como essenciais para a exploração mais sistemática das riquezas coloniais"7. Não existia, porém, uma política científica coerente. Os núcleos de pesquisa que então surgiram foram frutos de iniciativas isoladas, de necessidades imediatistas e conjunturais. O sistema de ensino superior, muito calcado no sistema francês, limitava-se a algumas poucas escolas profissionalizantes, que tinham como incumbência a formação dos elementos indispensáveis ao funcionamento da sociedade (engenheiros, médicos, militares e advogados) e eram destinadas prioritariamente aos descendentes das camadas dominantes. Neste quadro, a química desempenhava um papel apenas acessório por falta de uma Universidade ou, pelo menos, de uma Faculdade de Filosofia e Ciências, cuja fundação, já tentada pelos jesuítas em 1583, nunca teve sucesso. Ao contrário do que ocorreu nas antigas possessões espanholas do Continente, a química, em nenhum lugar se lecionou, se estudou ou se cultivou como atividade em si mesma.

A química produtiva surgiu no Brasil do trabalho dos mineralogistas, dos metalurgistas e dos farmacêuticos, incluindo-se 
aí, devido à estrutura específica do ensino superior no Brasil, os médicos e, mais tarde, os engenheiros. Se podemos caracterizar o século XIX como período formativo da ciência da química no País, é porque nele alguns professores de química implantaram, especialmente na segunda metade do século, as novas doutrinas científicas da época, através da publicação de obras significativas, dentre as quais algumas das melhores já produzidas no país. A atividade destes professores, porém, era de reprodução do conhecimento, em conseqüência, talvez, da secular educação escolástica. Ao contrário do que aconteceu nas ciências naturais descritivas, mais facilmente acessíveis às pesquisas individuais, as investigações originais em química formam raríssimas exceções, restringindo-se praticamente a uma importância apenas local. O fluxo de estudantes brasileiros em direção às universidades européias durante o Segundo Império, freqüentemente estimulado, com recursos próprios, pelo Imperador D. Pedro II, não resultou em mudança significativa desta situação, e, também, mais uma vez ao contrário do que sucedeu com outras ciências naturais, a colaboração de cientistas estrangeiros foi limitada e não deixou traços permanentes.

Dentro deste panorama geral, iremos fixar nosso trabalho no Rio de Janeiro, sede do governo imperial, onde se concentravam as atividades culturais, na Escola Politécnica e na figura de um eminente cientista estrangeiro que aqui se estabeleceu e ajudou a consolidar a pesquisa e o ensino de química: Wilhelm Michler.

\section{O ENSINO DE ENGENHARIA E A QUÍMICA}

No Brasil, o primeiro documento oficial que se conhece referente à formação de engenheiros é a carta régia de 15 de janeiro de 1699, de D. Pedro II, rei de Portugal (1648-1706), ao governador do Rio de Janeiro, determinando a criação de uma "Aula de Fortificação". Os civis podiam seguir o curso, que preparava conjuntamente engenheiros militares (ou de fortificações) e artilheiros. Dela foi professor por cerca de 30 anos o mais famoso engenheiro militar português do período colonial, José Fernandes Pinto Alpoim (1695-1765) ${ }^{8}$. Dentre as obras de Alpoim que sobreviveram está o Arco do Teles, na praça Quinze de Novembro, no Rio de Janeiro. Em 1792, o Conde de Rezende, então vice-rei do Brasil, criou no Rio de Janeiro a "Real Academia de Artilharia, Fortificação e Desenho", situada na Casa do Trem de Artilharia, na Ponta do Calabouço.

Logo após sua chegada, D. João VI percebeu a necessidade da instalação de outro Curso ou de uma Escola que formasse militares e engenheiros pois, interrompidas as comunicações com a Europa pelas guerras napoleônicas, estes profissionais começavam a rarear. Através da carta régia de 4 de dezembro de 1810 , foi criada no Rio de Janeiro, por inspiração do Ministro Conde de Linhares, a "Academia Real Militar”, para prover a Corte de oficiais e engenheiros à altura das necessidades do momento ${ }^{10}$.

As aulas da Academia Militar tiveram início em 23 de abril de 1811, na Casa do Largo de Artilharia, que então funcionava como Arsenal de Guerra, situada nas imediações do antigo Colégio dos Jesuítas, no morro do Castelo, no local onde hoje se ergue o Museu Histórico Nacional, perto do Aeroporto Santos Dumont. Pouco mais tarde, em 1 de abril de 1812, a Academia se instalaria definitivamente no antigo Largo da Sé Nova, atual Largo de São Francisco, no prédio que hoje, muito alterado, abriga o Instituto de Filosofia e Ciências Sociais da Universidade Federal do Rio de Janeiro. O edifício assumiu a partir de 1826 uma feição neoclássica e em seu pátio realizaram-se a I Exposição Nacional (1861) e a III Exposição Nacional (1873)*2.

\footnotetext{
*2 As Exposições Nacionais eram mostras organizadas para a divulgação e a promoção do desenvolvimento industrial. No período monárquico foram realizadas cinco Exposições Nacionais (1861, 1866, 1873, 1875 e 1889) e uma Exposição Industrial (1881).
}

A abertura desta nova instituição representou uma substancial melhoria no ensino das ciências no Brasil, ou, pelo menos, em seu planejamento, devido à ousadia de seu programa de estudos, de ampla diversidade e de abordagem profunda. Embora seu objetivo principal fosse o estudo da ciência militar, a Academia Real Militar foi estruturada de modo a se tornar um centro de estudos das "ciências exatas e de observação"10. Seu currículo incluía um curso completo de ciências matemáticas, física, química, mineralogia, metalurgia e história natural ${ }^{11}$. A Carta de Lei de 4 de dezembro de 1810 criou uma cadeira de química no $5^{\circ}$ ano, cujo lente “...dará todos os métodos docimásticos para o conhecimento das minas, servindo-se das obras de Lavoisier, Vauquelin, Jouveroi, de la Grange e Chaptal, para formar seu compêndio, onde fará toda a sua aplicação às artes e à utilidade que delas derivam"12. É interessante notar que as obras em que o professor de química deveria basear seu curso são todas de autores franceses e que não se recomendavam obras brasileiras ou portuguesas já existentes e de alta qualidade, como as de Vicente Coelho Seabra da Silva Telles e Manuel de Paiva.

Durante os primeiros anos dividiram a coordenação da nova cadeira de química o inglês Dr. Daniel Gardner (1785-1831) e o italiano general Carlo Antonio Maria Galleani Napione di Coconato, aqui conhecido como Carlos Antonio Napion (17581831), autor de vários estudos técnicos sobre química e que acumulava a direção da Academia (Napion foi também responsável pela organização da Fábrica de Pólvora da Lagoa de que existem vestígios no terreno do atual Jardim Botânico) ${ }^{13}$.

Daniel Gardner lecionava química no Colégio de São Joaquim desde 1809. Mais tarde, em 1837, o colégio passou a denominar-se Imperial Colégio de D. Pedro II. Gardner foi também grande propagador da Química, através de palestras anunciadas na Gazeta do Rio de Janeiro (1810). As experiências químicas realizadas durante as palestras garantiam o sucesso desses eventos, pois preenchiam a expectativa de uma platéia ávida por curiosidades científicas ${ }^{* 3}$. No entanto, o interesse prático era nenhum.

Em 1832, a Academia Real Militar fundiu-se com a Academia de Marinha para formar a Academia Imperial Militar, porém, o novo regulamento revelou-se conceitualmente muito inferior. $\mathrm{O}$ ensino de química e mineralogia limitava-se ao estudo das substâncias empregadas nas obras arquitetônicas e na pirotecnia. A maneira pela qual este programa era desenvolvido mostra uma concepção estritamente voltada para as aplicações, não havendo lugar para o desenvolvimento do espírito da dúvida ou da experimentação. Decorreram mais de vinte anos até que se restabelecesse o caráter mais científico da instituição.

As duas academias voltaram a se separar em 1833. Em 1839, a Academia Real Militar passou a ser denominada "Escola Militar", com um curso de engenharia realizado em cinco anos, ampliados para sete em 1842. Naquele ano, a alteração dos estatutos da Escola Militar assinala uma alteração importante em nosso ensino de ciências: a instituição deveria preparar "engenheiros hábeis para o melhoramento de materiais do país"".

No período de 1833 a 1846 sucederam a Gardner na cadeira de química, João da Silveira Caldeira (1800-1859) e frei Custódio Alves Serrão (1799-1873), que acumularam esta função com a de diretor do Museu Imperial.

O Ministro da Guerra, M. F. de Souza e Melo, em seu relatório de 1851 destaca: "...a nossa Escola tem todos os elementos para fazer sábios; poucos, porém, para formar oficiais"14, e este deve ter sido um dos argumentos para que fosse sancionado

\footnotetext{
*3 Este modo de divulgação científica já era utilizado pela "Royal Institution", na Inglaterra deste 1799, com o objetivo de “...difusão do conhecimento e facilitação da introdução de inventos, mediante cursos de preleções filosóficas e experiências, da aplicação da ciência aos fins comuns da vida”.
} 
o Decreto $\mathrm{N}^{\mathrm{o}} 2166$ de 1 de março de 1858, que desdobrou a Escola Militar em duas escolas: a Escola Militar, que foi primeiramente para a Urca e logo a seguir para a Praia Vermelha, e a Escola Central, que continuou no prédio do Largo de São Francisco, permanecendo sujeita, porém, ao regime militar. Com a reforma, os oficiais engenheiros deveriam estudar quatro anos na Escola Central e dois na Escola Militar ${ }^{10}$.

Em meados do século XIX na Europa, a química orgânica havia se desenvolvido rapidamente e representava um foco poderoso da pesquisa química e de discussões teóricas. No Brasil, apesar da variedade de recursos vegetais e animais, ainda não existia uma cadeira sobre a matéria, restringindo-se a química à chamada química mineral. A ausência de contato direto entre professores e os centros de pesquisas europeus dificultava a penetração de novas idéias ${ }^{15}$.

Em agosto de 1870, Paulino José Soares de Souza, ministro do Império, apresentou à Câmara uma proposta de reforma da Instrução Pública que incluía normas para a criação de uma Universidade. Declarou, textualmente, dever nela incorporar-se “...a Escola Central, verdadeira Faculdade de Ciências"16, propondo-lhe a designação de Faculdade de Ciências Naturais e Matemáticas, o que já indicava o caminho que levaria à Escola Politécnica, organizada em 1874.

Em 1874, após o término da Guerra do Paraguai, por iniciativa do Visconde do Rio Branco, a Escola Central passou do Ministério da Guerra ao Ministério do Império, tomou a denominação de Escola Politécnica e passou a ser destinada apenas a alunos civis. Pelo projeto original, a Escola Politécnica tinha a finalidade de formar, além de engenheiros e bacharéis, doutores em ciências físicas e naturais. Neste conjunto de alternativas apareceram as novas subdivisões da Química, a Química Inorgânica, a Química Analítica Mineral e Orgânica, a Química Orgânica e a Química Industrial, distribuídas pelos vários cursos da Escola e com obrigatoriedade de aulas práticas. O projeto foi prejudicado entretanto pela falta de livros, pela dependência da tradução de obras estrangeiras, pelo apelo mais à teoria do que à observação e às experiências, e pela pequena demanda de engenheiros. O resultado foi que a comunidade ligada à ciência foi sempre pequena demais para realizar qualquer trabalho original continuado, restando apenas as realizações individuais ${ }^{1}$.

Em 1896, já na República, os cursos científicos da Escola foram extintos pelo Decreto $n^{\circ} 2224$ do Ministro da Justiça, Antônio Gonçalves Ferreira. A decisão de extinguir os cursos científicos da Escola Politécnica foi justificada com base em sua reduzida procura, mas para alguns professores e alunos da época, a extinção fora o resultado prático da vigência, entre os politécnicos de então, de uma visão pragmatista da ciência, imposta pelo positivismo vitorioso com a instalação da República $^{17,18}$. No período de 1874 a 1896 temos a seguinte distribuição dos formandos: 32 bacharéis em ciências físicas e matemáticas, 37 bacharéis em ciências físicas e naturais, 13 engenheiros industriais (artes e manufatura), 8 engenheiros de minas e 209 engenheiros geógrafos.

Devido à ausência de docentes qualificados foi convidado para titular da cadeira de química mineral, em 1874, Joaquim Duarte Murtinho (1848-1911), que era médico e fora discípulo de Manuel Maria Moraes Valle (1824-1886). Para o ensino de física e química Industrial foi contratado para um período de três anos Charles Ernest Guignet, professor da Escola Politécnica e da Escola de Lavoisier, de Paris, proeminente pesquisador, criador do processo de preparação do óxido crômico (verde de cromo), que em sua homenagem é chamado de verde de Guignet, usado ainda hoje como pigmento para tintas. Guignet permaneceu no Brasil até 1879 , quando assumiu a direção da "Station agronomique de la Somme". Foi dele a primeira análise química das águas da Baía de Guanabara ${ }^{4}$, tendo sido autor de outras, como a da cafeína na erva-mate. Para a cadeira de Química Industrial do curso de Artes e Manufaturas foi contratado em 1884, Wilhelm Michler (1846-1889).
Intimamente ligado à Escola Politécnica, foi criado em 1860 o Instituto Politécnico Brasileiro que tinha como objetivos o estudo e a difusão dos conhecimentos teóricos e práticos dos diferentes ramos de engenharia e das ciências e artes acessórias. O Instituto caracterizou-se pela defesa dos interesses profissionais dos engenheiros, a partir da idéia de que a modernização material da sociedade dependeria da "proteção estatal" aos homens "cientificamente preparados". A revista do Instituto foi criada em 1868 e durou mais de 60 anos. O Instituto Politécnico foi uma espécie de antecessor da atual Academia Brasileira de Ciências, com a diferença das finalidades, conforme pode-se verificar no estatuto da Academia, “....concorrer para o desenvolvimento das ciências e das suas aplicações que não tiverem caráter profissional".

A história da Escola Politécnica sugere que se deve fazer uma distinção clara entre uma instituição destinada a transmitir idéias científicas recebidas de outros e uma instituição forçada pela demanda a ela feita pela Sociedade para fazer novas descobertas e desempenhar um papel ativo na comunidade científica internacional ${ }^{1}$.

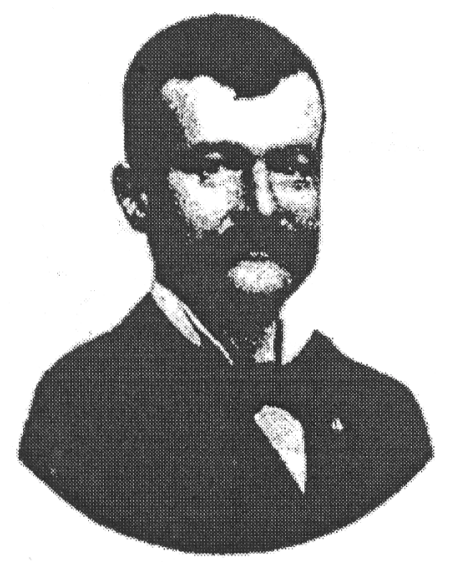

Figura 1. Retrato de Wilhelm Michler (Iconografia da Biblioteca Nacional) $* 4$

Dentre os destacados professores de Química da Escola Politécnica iremos focalizar o professor Wilhelm Michler, o descobridor da auramina (Figura 2), corante de uso na tinturaria devido à sua cor de ouro, muito conhecido também pela cetona aromática que traz seu nome (Figura 3). Nascido em 27 de dezembro de 1846, em Schmerbach, distrito de Mergentheim, em Württemberg, um dos pequenos estados alemães, fez seus primeiros estudos na Escola Normal de Tempelhof e, naquela cidade, foi auxiliar de professor público durante quatro anos. Entrou em 1870 para a Escola Politécnica de Stuttgart, onde estudou química por dois anos com Fehling e Victor Meyer. Ao se transferir para a Escola Politécnica Federal de Zurique, na Suíça, em 1871, o professor Victor Meyer convidou Michler para ser seu segundo assistente, cargo para o qual foi nomeado em março de 1873. Obteve o título de Doutor em Filosofia em 1874 pela Universidade de Zurique, sob a direção de Victor Meyer, com a tese intitulada "Contribuições para o Conhecimento das Combinações Orgânicas que Contêm Enxofre e Nitrogênio". Em 1875, o Conselho Federal de Instrução concedeu-lhe licença para ensinar química e nomeou-o primeiro assistente.

Adoecendo o professor Meyer, Michler foi encarregado da regência interina do curso de química. Foi nomeado professor

\footnotetext{
${ }^{* 4}$ Retificamos a informação dada por Rheinboldt ${ }^{11}$, "falta à literatura histórica da química um retrato de Michler"; agradecemos a indicação do professor Carlos Alberto L. Filgueiras (IQ/UFRJ).
} 


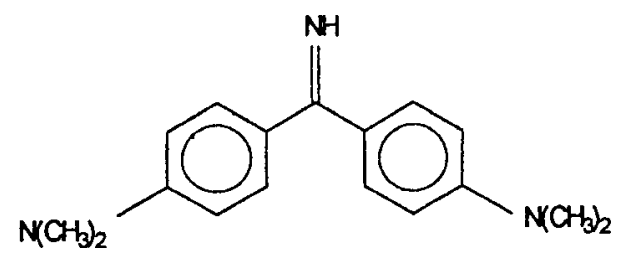

Figura 2. 4,4'-(imidocarbonil)-bis(N,N-dimetil-anilina), (auramina).

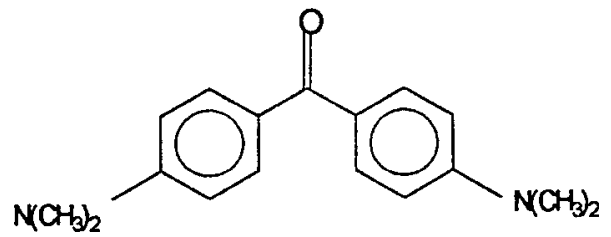

Figura 3. 4,4'-bis(dimetilamino) benzofenona, (cetona de Michler).

da Escola Politécnica de Zurique em 1878. Durante o período, Michler acumulou a regência da cadeira de Química na Escola Veterinária de Zurique e publicou 35 trabalhos experimentais que firmaram seu nome na história da Química ${ }^{19}, 20$.

Em agosto de 1881, Michler veio em licença à América do Sul, visitando primeiramente Buenos Aires e, em seguida, o Rio Grande do Sul e Santa Catarina. Hofmann, no necrológio escrito para o Beritche, afirma que Michler viajou de férias, mas com o propósito de realizar pesquisas ${ }^{21}$. Ao chegar ao Rio de Janeiro em novembro de 1882, Michler entrou em contato com Antônio Ennes de Souza, professor do curso de engenharia de minas, que também havia feito seu doutorado na Universidade de Zurique. Ennes o apresentou a Álvaro de Oliveira, professor da Escola Politécnica (atual Escola de Engenharia da Universidade Federal do Rio de Janeiro), que colocou a sua disposição os laboratórios de Química Inorgânica e de Metalurgia. Neste período, Michler publicou vários trabalhos sobre produtos naturais do Brasil, alguns dos quais na Revista de Engenharia (do Rio de Janeiro). Impondo-se à admiração dos professores e do diretor da Escola, o conselheiro Galvão, foi solicitada ao Ministério sua contratação. O livro de atas da Congregação da Escola Politécnica registra, na ata da sessão realizada em 28 de fevereiro de 1884 , a autorização dada para sua contratação para lecionar a cadeira de Química Industrial. $\mathrm{O}$ contrato, aprovado pelo Aviso $\mathrm{n}^{\mathrm{O}} 757$ de 23 de fevereiro de 1884 do Ministro do Império, o Conselheiro Francisco Antunes Maciel, foi sucessivamente renovado até seu falecimento, ocorrido em $1889^{19,20}$.

Pelas 45 horas e meia de aulas semanais que dava, Michler recebia quinhentos mil réis por mês, mas, gastando de seu próprio bolso algumas dezenas de contos de réis, conseguiu montar um laboratório correspondente às necessidades das técnicas mais modernas do trabalho químico experimental, transformando, assim, o antigo laboratório que tinha apenas dois bicos de gás e não tinha água corrente, nem aparelhos, drogas e material de ensino, em uma ala própria do prédio, com laboratórios confortáveis para o trabalho simultâneo de 30 alunos, sala de aula e sala de balanças, “...somente comparável aos melhores da Alemanha"19. Nas atas da Congregação da Escola Politécnica, encontram-se os balanços anuais dos gastos de cada laboratório com seus saldos ou déficits. $\mathrm{Na}$ ata de 4 de agosto de 1888 consta que foram lidos dois avisos do Ministro do Império, um indenizando Michler com a quantia de 3:352\$975, pelos gastos realizados no laboratório de química industrial nos exercícios de 1883 até 1886 e outro autorizando a aquisição de instrumentos para o referido laboratório ${ }^{22,23}$.

No laboratório trabalhavam grande número de alunos que afluíam para participar dos trabalhos analíticos e técnicos. Michler se preocupava sempre em procurar uma colocação para seus alunos. Outras atividades técnicas eram estimuladas. Existe, por exemplo, registro de uma autorização do Ministro do Império para a concessão de passagens para que Michler, acompanhado de seus alunos, visitassem o Engenho Central de Lorena, em São Paulo.

A contemporaneidade do curso de Química Industrial ministrado por Michler pode ser comprovado pelo programa datado de 1886 que apresentamos sob a forma de apêndice. Destacamos a sua preocupação com a tecnologia e com os trabalhos práticos.

Nos rascunhos das atas da Congregação da Escola Politécnica, encontradas no Arquivo Nacional, encontramos um horário escolar referente ao ano de 1885 , de onde destacamos as disciplinas da área de química. Cada disciplina tinha dois professores: o professor responsável e um bacharel (formado em ciências), responsável pela "recordação", uma espécie de aula de reforço. Na falta deste último, o professor da disciplina era também responsável por estas aulas ${ }^{22}$ :

Michler completou diversos trabalhos, só em parte publicados, sobre produtos naturais brasileiros desconhecidos fora do País. Na Revista de Engenharia (do Rio de Janeiro) de 1883, encontramos a série de trabalhos "Investigações Químicas dos Produtos Naturais do Brasil“" 24 (Figura 4) com participação de Antônio Sampaio, um seu discípulo que havia obtido o doutorado em Zurique e com o qual já havia publicado anteriormente um trabalho experimental, "Zur Kenntnis der Diamidoditolylverbindungen", no Berichte der Deutschen Chemischen Gesellschaft de 1881. Neste mesmo número do Berichte podese encontrar ainda outros seis trabalhos de Michler com colaboradores diferentes, todos estrangeiros.

$\mathrm{O}$ primeiro trabalho da série que Michler publicou na $\mathrm{Re}$ vista de Engenharia (do Rio de Janeiro) tem como título "Sobre a Matéria Graxa da Urucuba". Nele se faz uma detalhada análise da graxa da urucuba ou bicuíba, em Pernambuco ${ }^{25}$ [Virola gardneri (DC.) Warb.], tendo sido a primeira vez em que se verificou a presença do glicerídeo do ácido mirístico numa gordura vegetal. O produto poderia ser utilizado como substituto da Dika ou Adika, exportada das colônias africanas e utilizadas na fabricação de velas e de sabão. Infelizmente, o trabalho não foi publicado em revista de divulgação internacional, embora houvesse previsão para tal. No segundo trabalho da série, "Sobre a Matéria Graxa do Tingui", estudou o óleo do fruto do tingui [Magonia pubescens St. Hil.], um arbusto muito abundante no cerrado do Piauí e do Ceará. A análise então feita prova a existência de tristearina na parte sólida e trioleína na parte líquida. Este trabalho destaca-se por discutir

\begin{tabular}{lccc}
\hline Disciplina & $\mathbf{N}^{\mathbf{0}}$ de aulas semanais & Duração de cada aula & Professor Responsável \\
\hline Química Inorgânica & 03 & $9 \mathrm{~h} 45 \mathrm{~min}$ & Conselheiro Bacharel Álvaro J. de Oliveira \\
Recordação & 01 & $9 \mathrm{~h} 45 \mathrm{~min}$ & Bacharel F. A Carneiro da Cunha \\
Química Orgânica & 03 & $2 \mathrm{~h}$ & Dr. A Getúlio das Neves \\
Recordação & 01 & $2 \mathrm{~h}$ & O professor interinamente \\
Química Analítica & 03 & $2 \mathrm{~h}$ & Dr. E. Firmo Martins \\
Recordação & 01 & $11 \mathrm{~h}$ & O professor interinamente \\
Química Industrial & 03 & $11 \mathrm{~h} 30 \mathrm{~min}$ & Dr. Wilhelm Michler \\
Recordação & 01 & $12 \mathrm{~h}$ & O professor interinamente \\
\hline
\end{tabular}




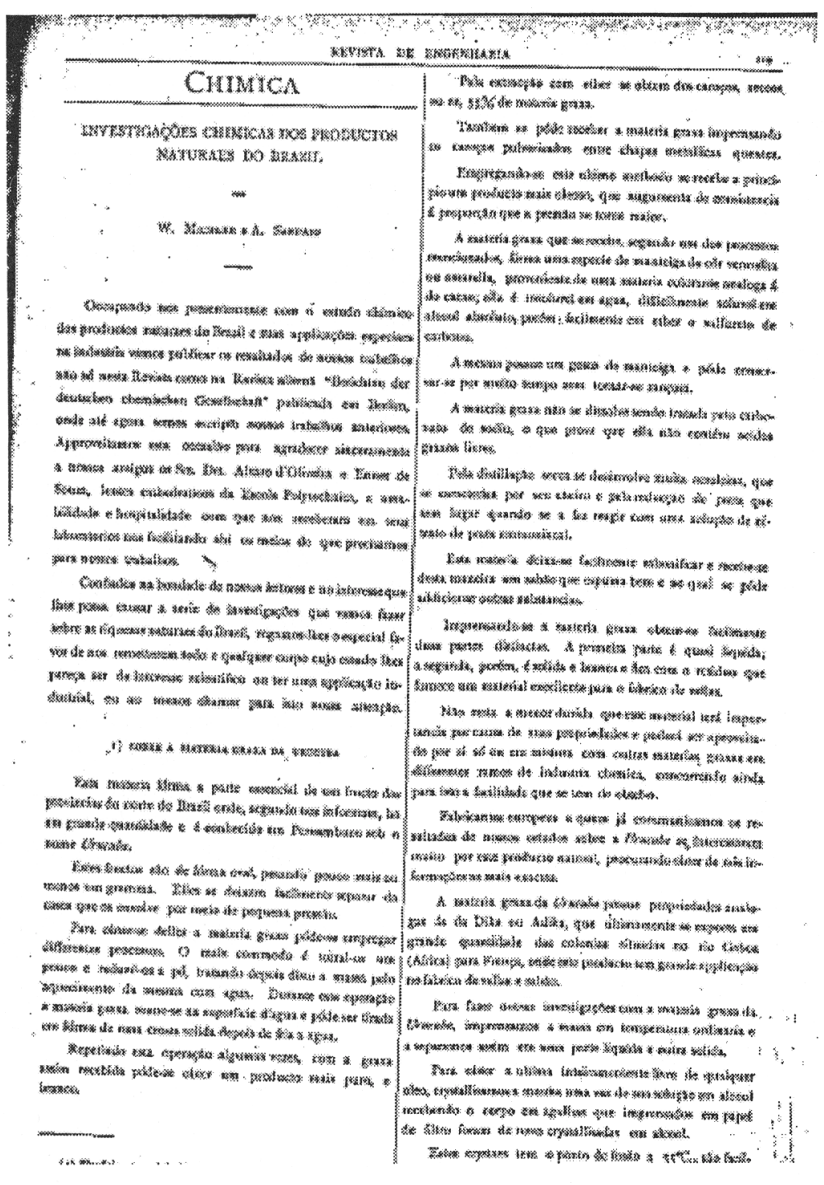

Figura 4. Primeiro trabalho publicado por Michler no Brasil [Revista de Engenharia, 1883].

minuciosamente a natureza dos constituintes químicos do fruto do tingui, que é empregado até hoje na fabricação local de sabão, o chamado "sabão de tingui" 25 . No terceiro trabalho, o menor deles, denominado "Sobre o alúmen do Piauhy" faz-se uma análise quantitativa total do alúmen extraído no Piauí comparando-o, pela qualidade, aos alúmens extraídos em Nápoles e em Roma ${ }^{24}$.

$\mathrm{Na}$ Revista de Engenharia podemos encontrar outras notícias sobre a atuação de Michler na Escola Politécnica, os atos de autorização da renovação de seu contrato, indícios de que o Ministério da Agricultura enviava ao Laboratório de Michler, na Escola Politécnica, diversos materiais para serem analisados, como a fécula de Mucunã. A Revista destaca também a visita realizada por D. Pedro II à Escola Politécnica e seu interesse nas análises realizadas por Michler e seus alunos sobre as matérias graxas e várias gomas. A última notícia publicada sobre Michler na Revista é o voto de pesar dos membros do Instituto Politécnico, aprovado na sessão de 4 de dezembro de 1889 , por seu falecimento ${ }^{26}$.

As análises realizadas por Michler para o Ministério da Agricultura deram origem a uma série de trabalhos, intitulada "Comunicações do Laboratório de Química Industrial da Escola Politécnica"27,29,30,31,32, publicada na Revista Agrícola, do Imperial Instituto Fluminense de Agricultura (Rio de Janeiro), em 1889 (Figura 5). Na mesma revista, em 1885 (Vol. XVI), Michler publicou, sob o título geral "Trabalhos do laboratório de química industrial da Escola Politécnica", o trabalho "Sobre a matéria graxa das sementes da trepadeira Fevillia trilobata $L$. (nhandiroba ou andiroba)"32. Esta trepadeira usada como purgativo, muito abundante nas províncias do norte do país, foi analisada por Michler e por Theodoro Peckolt ${ }^{33}$, com o objetivo de

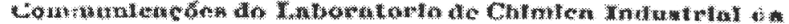

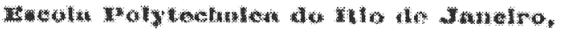
pelo Nr. NW. Mriehro:

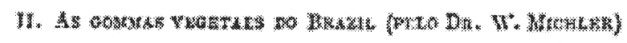

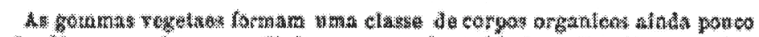

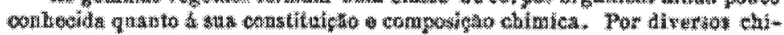

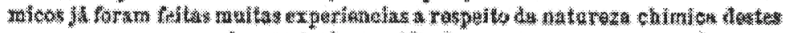

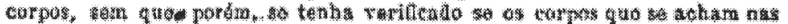

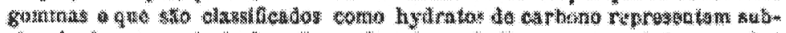

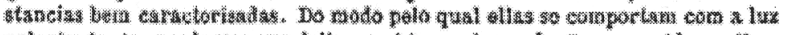

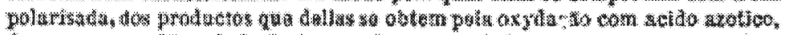

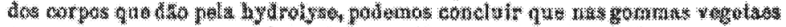

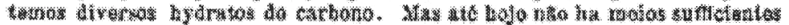

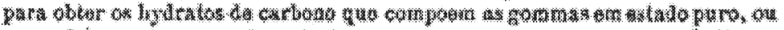

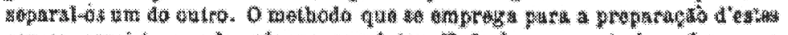

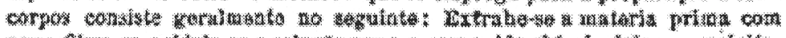

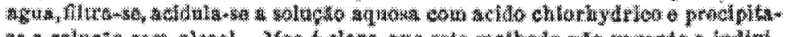

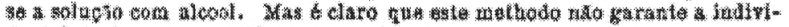

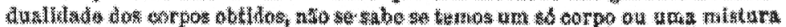

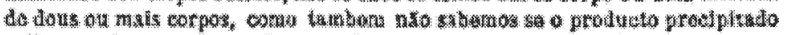

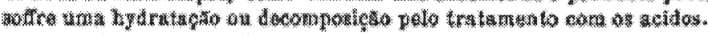

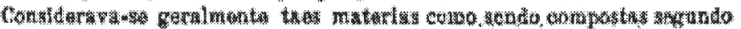

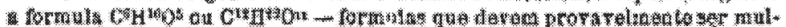

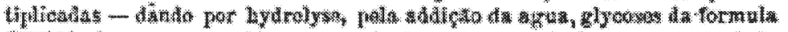

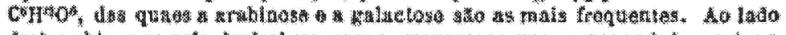

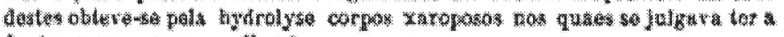
dextrose ou coryos watrellunter.

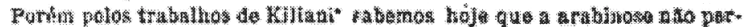

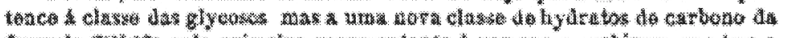

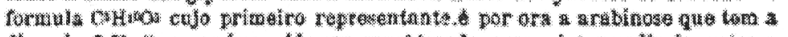

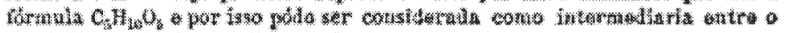

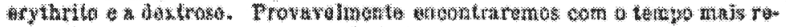

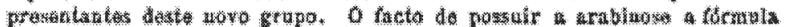

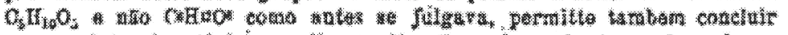

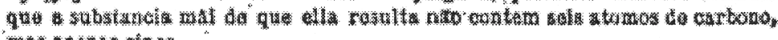
mine aranas cinca.

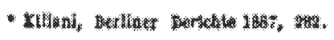

Figura 5. Trabalho publicado na Revista Agrícola do Imperial Instituto Fluminense de Agricultura, 1889.

empregá-las no fabrico de matérias graxas. Michler executou suas análises a partir do óleo obtido da maceração das sementes e identificou o ácido palmítico e o ácido oléico. O trabalho de Tulloch e Bergter (1976) ${ }^{34}$ confirma a composição do óleo através da análise por ${ }^{13} \mathrm{C}$ RMN como sendo $31 \%$ de ácido palmítico, $12 \%$ de ácido esteárico, $11 \%$ de ácido oléico, $7 \%$ de ácido linoléico, 30\% de ácido cis,trans,cis-9,11,13-octadecatrienóico e 9\% de ácido cis,trans,trans-9,11,13-octadecatrienóico.

O primeiro trabalho feito para o Ministério da Agricultura intitula-se "Estudo Sobre a Fécula da Mucunã"27. A fécula era obtida da raiz e das sementes da Mucunã, planta oriunda do Ceará, uma Leguminosa dos gêneros Mucuna e Dioclea, produtora de sementes e raízes amiláceas ${ }^{25}$, a qual é usada nos tempos de seca como alimento. Segundo Rodolpho Theophilo, em sua monografia da Mucunã, além da irritação da pele causada pelo manuseio das vagens, o uso da fécula como alimento produz diversos incômodos tais como desarranjos, sensação de peso no estômago e digestão difícil. Ao verificar a presença ou não de alcalóide tóxico, Michler identificou um ácido tânico em grande quantidade. Apesar de não tê-lo isolado, Michler afirma tratar-se de um novo tipo de ácido tânico, ao qual denominou "ácido tânico da Mucunã". Michler isolou também o corante vermelho "phlopapheno da Mucunã". A análise quantitativa da fécula impura deu como resultado os seguintes valores:

$\begin{array}{lr}\text { Água } & 22,12 \% \\ \text { Amido } & 75,82 \% \\ \text { Celulose } & 0,51 \% \\ \text { ácido tânico e phlopapheno } & 0,74 \% \\ \text { cinza } & 0,92 \% \\ \text { corpos solúveis no éter } & 0,31 \% \\ \text { corpos azotados } & 0 \%\end{array}$


Os resultados da análise levam Michler a concluir que a fécula, enquanto alimento exclusivo, tem pouco valor nutritivo, só devendo ser usada em combinação com outros alimentos que contenham albumina e gorduras. Considera o ácido tânico nocivo ao organismo e recomenda que ele deve ser eliminado ou reduzido ao mínimo, pois ataca a mucosa.

Michler realizou um ensaio em que empregou o ácido tânico da Mucunã para curtir a pele de boi. Ele chama a atenção também para o corante, "...chamam-se phlopaphenos os corpos amorfos vermelhos que se acham nas cascas de diversas plantas e que são solúveis em álcool diluído e nos álcalis", citando trabalhos de Hesse, Hlasiwetz e Bottinger. Este trabalho foi citado na seção "Noticiário" da Revista de Engenharia (do Rio de Janeiro) ${ }^{26}$. O veneno da mucunã pode ser parcialmente eliminado pela água: os sertanejos dizem: "a mucunã, quando suja, mata; quando lavada faz mal"28.

A alimentação com mucunã pode levar ao latirismo, provocado pela ingestão de certos aminoácidos ${ }^{*} 5$ como os encontrados em feijões africanos. Animais de laboratórios alimentados com mucunã não se desenvolvem bem [informação pessoal do prof. Nuno Alvares Pereira].

No segundo trabalho desta série, intitulado "Sobre As Gomas Vegetais do Brasil" 30 , Michler apresenta um estudo sobre a goma de angico, em que descreve todos os passos da análise e os diversos ensaios realizados. Ele cita os trabalhos de Scheibler, Killiani, Claësson e O'Sullivan sobre os produtos obtidos das análises de gomas arábicas. Assim como nos trabalhos publicados na Revista de Engenharia (do Rio de Janeiro), esta série contém em rubrica a afirmação de que terão continuidade, porém não encontramos nada mais a respeito dos mesmos.

$\mathrm{O}$ terceiro trabalho, intitulado "Sobre Alguns Óleos Vegetais do Brasil" 30 , apresenta a análise dos óleos de oiticica (Licunia rigida) e de nhandiroba e descreve a influência do ar e da luz sobre os óleos de buriti (Mauritia vinifera), de tingui, de nhandiroba e de cumaru (Dypterix odorata).

Rizzini e Mors ${ }^{25}$ afirmam que fez-se em 1876, em Fortaleza, a primeira tentativa de exploração industrial do óleo de oiticica [Licania rigida Benth], por sugestão do botânico Francisco Freire Alemão, para aproveitar as propriedades secativas deste óleo, que tem uso na indústria de tintas e vernizes. A exploração em escala começou a ser significativa a partir de 1927.

No volume XX (1889) da Revista Agrícola do Imperial Instituto Fluminense de Agricultura, além do necrológio escrito pelo presidente da entidade, Hermillio Bourguy Macedo de Mendonça ${ }^{19}$, encontramos a publicação de um trabalho póstumo "A manteiga de Pequi" 31 , em que Michler faz a análise da matéria graxa do óleo obtido do fruto da Caryocar brasiliensis. Camb., o pequi do Pará ou do Amazonas, muito utilizado pelos habitantes do norte como tempero de comida. O fruto gera boa quantidade de um óleo, empregado na preparação de sabão, e as sementes contém uma gordura, em tudo semelhante à "manteiga de pequiá" (Caryocar villosum). Devido aos dois produtos gordurosos que fornece, Rizzini e Mors ${ }^{25}$, recomendam o pequi para uma futura agricultura nos cerrados.

O professor Michler foi sócio do Instituto Politécnico Brasileiro, admitido na categoria de sócio efetivo em 20 de agosto de 1884, em uma sessão sob a presidência do Conde d'Eu, juntamente com seu discípulo Antônio Sampaio. É interessante notar que não encontramos registro de nenhum outro trabalho desenvolvido por Antônio Sampaio, nem de seu paradeiro. Michler foi indicado, na sessão de 13 de abril de 1887, para apresentar o relatório da seção de indústria fabril na solenidade de comemoração do $25^{\circ}$ Aniversário da criação do Instituto, que se realizou em Sessão Magna no dia 17 de dezembro de 1887 (Figura 6). A indicação foi publicada na Revista de Engenharia (do Rio de Janeiro), em 28 de abril de 1887.

\footnotetext{
*5 "Aminoácidos do tipo $\alpha$ e $\beta$-aminopropionitrila" (De acordo com notação da época).
}
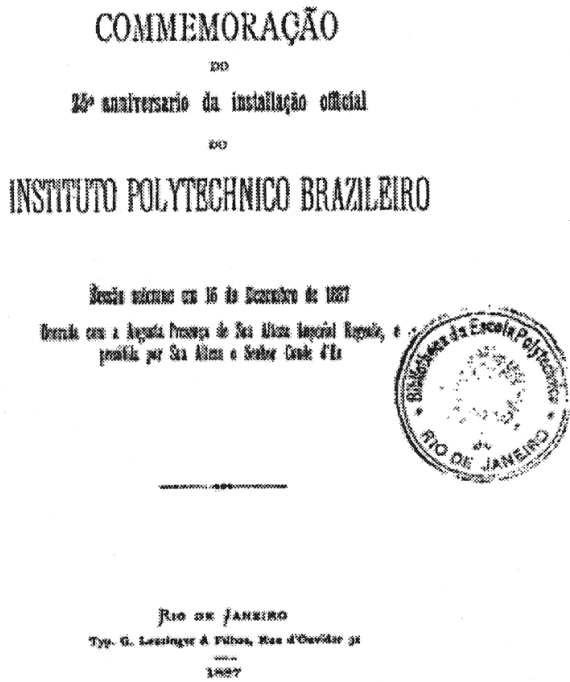

Figura 6. Capa da publicação comemorativa dos 25 anos do Instituto Politécnico Brasileiro, 1887.

A publicação dos trabalhos da sessão comemorativa inclui o relatório de Michler, com 13 páginas, nas quais faz a análise das indústrias instaladas no país, dando ênfase à necessidade de se ter pessoal técnico em todas as indústrias, de modo a se obter melhoria técnica e prática. Nele, Michler enfatizou as características do Curso de Artes e Manufaturas da Escola Politécnica e conclamou o governo a obrigar as indústrias a contratar os profissionais por ela formados. Ele cita o alto custo do trabalho manual e as elevadas tarifas do transporte ferroviário como outras dificuldades para o maior desenvolvimento da indústria. Também conclui da necessidade do país começar a fabricar produtos químicos, principalmente ácido sulfúrico e soda. Através da leitura deste relatório podemos ter uma idéia do estado de desenvolvimento industrial do país no fim do século XIX. Em seu relatório, Michler examinou as seguintes indústrias, caracterizando sua produção e localização ${ }^{35}$ :

1. Fabricação de ácido sulfúrico e de álcalis - Apesar do enxofre $^{*} 6^{3}$ ser encontrado no país, este ramo da indústria achava-se pouco desenvolvido. Existia, em São Paulo, uma fábrica de ácido sulfúrico, fabricado na concentração de $66^{\circ}$ Baumé (93\% $\mathrm{H}_{2} \mathrm{SO}_{4}$, em massa), através do processo de oxidação do enxofre por salitre. Importava-se enxofre da Sićlia*7, uma vez que o nosso sairia muito caro devido aos custos de transporte e exploração. Soda e potassa eram fabricadas em pequenas quantidades, usando-se a cinza de árvores, para serem empregadas na fabricação de sabão. Michler critica a não utilização da vinhaça (resíduo da destilação da aguardente), apesar de rica em sais de potássio. O cloreto de sódio era extraído da água do mar por evaporação ao ar livre, um processo que Michler considerava primitivo*8.

2. Fabricação de gelo e águas minerais - O gás carbônico empregado era produzido a partir de giz e ácido sulfúrico. Havia, porém, uma fábrica no Rio de Janeiro que empregava o gás carbônico produzido na fermentação de vinho. O gelo era fabricado em diversas cidades sendo que no Rio de Janeiro uma das fábricas produzia 3.000 toneladas anuais pelo processo do gás sulfuroso.

\footnotetext{
${ }^{* 6} \mathrm{O}$ Brasil não possui enxofre, somente pirita $\left(\mathrm{FeS}_{2}\right)$, assim o processo, hoje, é antieconômico.

${ }^{* 7}$ Atualmente importamos da Espanha e dos Estados Unidos.

*8 Este processo é utilizado ainda hoje e é econômico.
} 
3. Fabricação de vidros e cerâmica - A fabricação de vidro era explorada somente por duas fábricas que fabricavam objetos simples, a fábrica do Rio de Janeiro empregava para a fusão do vidro um regenerador de Siemens. Os objetos de cerâmica eram feitos em pequenos estabelecimentos em quase todo o País. Apesar de em diversos pontos do Brasil existirem jazidas de caulim ${ }^{* 9}$, a matéria prima da fabricação de porcelana, ainda não existia nenhuma fábrica

4. Fabricação de explosivos e inflamáveis - O governo possuía três fábricas para fornecimento do exército. Em São Paulo em 1886 montou-se uma fábrica de fósforos, “...que imitam os de Johnköpings".

5. Aproveitamento de resíduos animais - Indústria desenvolvida principalmente no Rio Grande do Sul. O país possuía duas fábricas de cola animal, usada em marcenaria. Existia, em Pelotas uma fábrica de guano artificial cuja produção era quase toda exportada para a Europa. Existia, no Rio de Janeiro, uma fábrica de carvão animal, em que se empregava somente ossos, cuja produção era integralmente consumida pelas refinarias de açúcar. Para curtir os couros, usava-se tratar as peles primeiro com cal e depois com substâncias tais como as cascas de canafistula, barba-timão, angico, mangue etc., ricas em ácido tânico.

6. Fabricação de matérias graxas - É descrita por Michler como uma importante fonte de riqueza para o País. Em diversos lugares existiam pequenas indústrias de óleos vegetais. Existia, no Rio de Janeiro, uma grande fábrica em que se fabricava e refinava o óleo extraído do caroço de algodão, o óleo de rícino (mamona) e o óleo de gergelim. Esta fábrica produzia também a miristina da bicuíba e da ocuba $^{*}{ }^{10}$ (matéria graxa sólida com uma consistência igual à do sebo de boi), considerada excelente matéria prima para sabões e velas. As fábricas de sabão eram as mais numerosas. Há poucos anos tinha se iniciado em Porto Alegre a fabricação de sabonetes, porém, como eram lançados no mercado como marcas estrangeiras, não eram conhecidos como sendo um produto nacional. Era grande o número de pequenas fábricas de velas. Na corte existia uma fábrica de velas de estearina. A cera de carnaúba, um produto das indústrias do norte do País, era utilizada na fabricação de velas e exportada para a Europa, onde era beneficiada.

7. Tinturaria e impressão de tecidos - Esta indústria era pouco desenvolvida no País. Encontrava-se, em anexo às tinturarias, uma seção de lavagem química, cuja finalidade era a limpeza com benzina das manchas e nódoas dos vestuários. Quanto à impressão de tecidos, o Brasil possuía somente uma fábrica, situada em São Paulo, que produzia chitas. Os corantes usados eram anilina e alizarina.

8. Fabricação de gás de iluminação - O gás de iluminação era usado em quase todas as cidades importantes. A matéria prima empregada era, em geral, o carvão de pedra de procedência inglesa. Michler propunha a utilização das águas amoniacais e do alcatrão para a fabricação de hidrocarbonetos aromáticos e fenóis.

9. Fabricação de açúcar e indústrias das fermentações - A fabricação de açúcar era a única grande indústria na época. Apesar do constante melhoramento dos processos empregados, Michler propõe a introdução do processo de difusão, para melhor rendimento do açúcar extraído da cana. $\mathrm{O}$ álcool obtido era geralmente de $20-21^{\circ}$ Cartier $(41 \%$ de etanol em volume). A matéria prima era a cana-de-açúcar. Existiam muitas fábricas de vinho e de cerveja espalhadas pelo País.

10. Fabricação de papel - Indústria muito pouco desenvolvida. Perto do Rio de Janeiro existia uma fábrica de papel ordinário que só era empregado em embalagens.

\footnotetext{
$* 9$ Caulim $-\left[\mathrm{Al}_{2} \mathrm{O}_{3} \cdot 2 \mathrm{SiO}_{2}\right]_{2} \cdot 3 \mathrm{H}_{2} \mathrm{O}$.

*10 sebo de ucuuba.
}

11. Fabricação de oleados - Existia somente uma fábrica, no Rio de Janeiro, ligada a uma fábrica de couros. A impressão das cores era feita à mão.

Michler faleceu às 5 horas da manhã do dia 27 de novembro de $1889^{19,20}$, sem deixar descendência, tendo sido enterrado no carneiro $\mathrm{n}^{\mathrm{o}} 83$ do quadro dos protestantes do cemitério de São Francisco Xavier, no Caju, Rio de Janeiro. No necrológio de Hermilio Mendonça para a Revista Agrícola, encontramos a transcrição de uma representação feita ao Senado pelos alunos do Curso de Artes e Manufaturas da Escola Politécnica, na qual fica evidente o apreço que tinham por Michler, num documento com cento e oitenta e três assinaturas, datado de 1887, em que eles relatam os esforços de Michler para a montagem do laboratório, o crescimento da freqüência de alunos, a existência de um livro de resultados de análises (este não foi encontrado por nós, nem na Biblioteca de Obras Raras da Escola de Engenharia da UFRJ, nem no Museu da referida instituição), e enumeram as análises realizadas a pedido do governo. O principal objeto desta representação seria o de protestar quanto à iniciativa de dividir a cadeira de química industrial em duas, suprimindo-se o lugar de substituto, e que se aprovada resultaria na saída de Michler da cadeira. É interessante notar que encontramos na Biblioteca de Obras Raras uma tese para preenchimento da vaga de professor substituto da cadeira de química industrial, de autoria de Willian Roberto Lutz ${ }^{36}$, na qual, ao contrário de outras existentes na mesma, não há referência à comissão julgadora. Consta que Alvaro de Oliveira apresentou proposta à Congregação da Escola Politécnica, para que fosse chamado o professor contratado de Química Industrial (Michler) para tomar parte da referida comissão ${ }^{23}$. Nas Atas da Congregação pudemos constatar que o Governo Imperial não homologou o resultado do concurso, realizado em junho de 1888, e o candidato não pode tomar posse. Lutz fez uma dissertação sobre a extração do sal marinho e a fabricação de soda, com mapas ilustrativos das regiões produtoras.

O necrológio escrito por August Wilhelm Hofmann ${ }^{21}$, confirma o prestígio de Michler junto à comunidade internacional. Hofmann apresentou um resumo dos trabalhos desenvolvidos por Michler ainda na Alemanha. Mencionou o fato de Michler ter sido convidado a assumir a direção de uma estação experimental de química agrícola, fato este que não nos foi possível confirmar. Hofmann afirmou também que Michler havia decidido deixar de colaborar com o governo brasileiro logo após a deposição de D. Pedro II, e se refere como causa mortis um acidente com um bonde-de-cavalos.

Em outro necrológio, escrito por Álvaro de Oliveira para a Gazeta de Notícias do Rio de Janeiro ${ }^{20}$ consta que os corpos docente e discente da Escola Politécnica planejaram colocar seu busto em bronze no Laboratório de Química Industrial. Acreditamos que esta homenagem final ao professor não tenha sido feita, porque não há indicação disto em nenhuma das Atas da Congregação da Escola Politécnica e a obra não consta do acervo do Museu da Escola de Engenharia da Universidade Federal do Rio de Janeiro, instituição originada da Escola Politécnica.

\section{APÊNDICE}

\section{PROGRAMA DO CURSO DE CHIMICA INDUSTRIAL - ESCOLA POLYTECHNICA - RIO DE JANEIRO, IMPRENSA NACIONAL, 1886.}

1. Métodos Gerais

2. Tecnologia d'água: reações d'água, água pluvial, água das fontes, águas frias, águas quentes, águas minerais, água potável, de drenagem, dos lagos, dos mares - Análise qualitativa e quantitativa das águas. Dureza d'água - Emprego Purificação - Abastecimento - Águas minerais artificiais: matérias primas, máquinas e aparelhos. 
3. Tecnologia do ácido sulfúrico, dos alcalis e indústrias correlatas.

Ácido sulfúrico - Matérias primas: piritas, enxofre, salitre, ácido azótico - Análises - Fornos de enxofre e pirita, camadas de chumbo, nitrose, purificação e concentração do ácido sulfúrico - ácido sulfúrico de Nordhausen, processo da Bohemia, processo Winkler, resíduos.

Clorureto de sódio, sal gema, águas salinas e do mar, águas mães, bromo.

Soda: soda natural, cinzas, águas mães, fabrico de iodo, regeneração do enxofre, soda artificial, processo Leblanc, sulfato de sódio, fornos, ácido clorídrico, sulfato segundo Hargreaves e Robinson. Transformação do sulfato em carbonato, fornos, soda bruta. Refinação. Regeneração do enxofre. Hidrato de sódio. Soda artificial segundo o processo de amoníaco, aparelhos; soda artificial por meio de Kryolitho - sulfito e hiposulfito de sódio, hipocloritos de sódio, potassa e cálcio, peróxido de manganês, regeneração, bórax e ácido bórico, permanganato de potássio.

Potassa natural: perlash, stocash, potassa da vinassa e suor de lã, águas mães, resíduos.

Salitre: terras salitrosas, salitre artificial, processo do Chile, transformação do salitre de sódio em salitre de potássio, ferro e ferri-cianuretos de potássio, sulfocianatos, vidro solúvel, bicromato de potássio.

4. Tecnologia do amoníaco: fabricação de gás, destilação das águas de gás, aparelhos de Lunge, Malet e Rose. Sais de amônio.

5. Cal virgem: fornos. Gesso: fornos. Cimento romano e de Portlandia.

6. Pedra ume.

7. Tecnologia dos vidros

Matéria prima. Análises. Fornos e aparelhos., vidro branco, vidros de garrafa, tubos de vidro, vidro de cristal, vidro de Bohemia, vidro para vidraça e espelhos. Coloração dos vidros.

8. Cerâmica

Matéria prima. Análises. Porcelana, granito, louça. Fornos e aparelhos.

9. Fabricação ultramarina.

10. Resíduos obtidos na fabricação dos metais: arsênico, ácido arseniosos e arsênico, realgar, ouro-pimenta, sulfato de ferro, zinco e cobre.

11. Matérias graxas.

Matérias primas de origem animal e vegetal. Métodos de extração - sulfureto de carbono - máquinas e prensas. Refinação. Velas de sebo, de estearina, de cera, de carnaúba, de espermacete. Glicerina - óleos minerais, parafina.

Fabricação de sabão: sabões de sódio e potássio, de sebo, de óleo de palmeira, de óleo de coco, de ácido oleico, de resinas, sabões medicinais.

Sabonetes: sabonetes transparentes, de glicerina, sabão em pó, emulsões, análises.

12. Tecnologia dos óleos essenciais. Métodos de extração.

13. Tecnologia dos hidratos de carbono.

Amido: matérias primas. Fabricação. Dextrina. Açúcar de cana e de beterraba, diversos processos de fabricação. Análises. Fabricação de celulóide.

14. Fabricação de álcool e bebidas alcóolicas.

Matérias primas. Fermentação - álcool, vinhos, cervejas, álcool metílico. Análise.

15. Fabricação de vinagre e do ácido acético. Análise - ácido oxálico, tartárico e cítrico.

16. Matérias corantes.

a) cores minerais de bário, cromo, ferro, manganês, cobalto, cobre, mercúrio, cádmio, chumbo, urânio, ouro, zinco, estrôncio, estanho, tungstênio,

b) cores de anilina: matérias primas: alcatrão, hidrocarbureto, álcoois, ácidos e bases provenientes do alcatrão. Fucsina, safranina, azul de anilina, de difenilamina, verde de iodo, de dimetilanilina, cores provenientes das combinações azo e diazo, cores dos fenóis, eosina, etc.

c) cores de naftalina;

d) cores de antracena;

e) cores de alizarina

f) cores de animais e vegetais.

17. Sobre branqueamento e tinturaria.

Fibras, branqueamento, mordentes, tinturaria de seda, linho, algodão e rami, por meio de cores minerais e orgânicas. Impressão de tecidos.

18. Produtos provenientes do resíduos animais.

Albumina, couro, pergaminhos - carvão animal, ossos, cola, fósforos, estrumes naturais e artificiais.

19. Tecnologia das resinas - borracha e guta percha.

20. Tecnologia dos vernizes, lacres e argamassas.

21. Tecnologia dos corpos explosivos.

22. Sobre alimentos.

\section{Trabalhos Práticos}

O laboratório estará aberto das 8 horas até 6 1/2 horas da tarde.

$1^{\mathrm{a}}$ parte: Análise qualitativa: 50 análises. Análise volumétrica completa. Análise quantitativa.

$2^{\mathrm{a}}$ parte: Continuação da análise quantitativa. Preparação de produtos químicos

$3^{\mathrm{a}}$ parte: Preparação de produtos químicos. Métodos químicos-técnicos.

Para os alunos mais adiantados tomarei em consideração a profissão que se quiserem dedicar, dando-lhes trabalhos análogos a essa profissão.

Os alunos adiantados que quiserem aperfeiçoar-se na química terão ocasião de fazer trabalhos científicos.

Rio de Janeiro, 26 de novembro de 1885

Wilhelm Michler

\section{REFERÊNCIAS}

1. Stephan, N.; Gênese e Evolução da Ciência Brasileira, Rio de Janeiro, ed. Arte-Nova S.A/ FIOCRUZ, 1976; cap. 2.

2. Schwartzman, S.; Formação da comunidade científica no Brasil, Rio de Janeiro, FINEP, 1979; pp. 46-47.

3. Dias, M. O. S.; RIHGB, 1968, 105-170.

4. Gonçalves, A L., Difusão da Química no Brasil, 18081934, Rio de Janeiro, Sobreondas, 1993; pp. 14-15.

5. Filgueiras, C. A L.; Quím. Nova 1985, 11, 263.

6. Ferraz, M. H. M.; As Ciências em Portugal e no Brasil (1772-1822): o texto conflituoso da química, São Paulo: EDUC, 1997; p191.

7. Dantes, M. A. M.; Relações científicas e tradições locais, in Goldfarb, A. M. Alfonso (coordenador), História da Ciência: o mapa do conhecimento, São Paulo/ Rio de Janeiro, EDUSP/Expressão e cultura, 1995, pp. 923-931.

8. Escola de Engenharia, UFRJ.; Home page (www.ee.ufrj.br)

9. Filgueiras, C. A. L.; Quím. Nova 1990, 13, 222.

10. Barata, M.; Escola Politécnica do Largo de São Francisco, berço da engenharia brasileira, Rio de Janeiro, Associação dos Antigos Alunos/ Clube de Engenharia, 1973; p. 20.

11. Rheinboldt, H.; Azevedo, F.; In As Ciências no Brasil, volume 2, Rio de Janeiro, Editora Melhoramentos, 1955, pp. 17-23.

12. Moacyr, P.; A Instrução e o Império (1823-1853), São Paulo, Cia. Editora Nacional, 1936 (Coleção Brasiliana, vol. 66), pp. 49 e 51. 
13. Carrara, E. e Meirelles, H.; A Indústria Química e o desenvolvimento do Brasil (1500-1889), Tomo I, Rio de Janeiro, Metalivros, 1996.

14. Holanda, S. B. de (organizador); História Geral da Civilização Brasileira, São Paulo: DIFEL, 1968; p. 238.

15. Mathias, S.; Revista de História, 1975, LXIII .

16. Lobo, F. B.; Uma Universidade no Rio de Janeiro, Rio de Janeiro, 1967.

17. Ferreira, L. O.; Ciência Hoje 1993, 16, 32.

18. Filgueiras, C. A L.; Quím. Nova 1986, 9, 263.

19. Mendonça, H. B. M. de; Revista Agrícola 1889, 20.

20. Oliveira, A. J. de; Gazeta de Notícias 1889, 232.

21. Hofmannn, A. W.; Ber. Deutschen Chemischen Gesellschaft, 1890, Berlim, XXIII (3-6).

22. Arquivo Nacional, IE 468, rascunhos das Atas da Congregação da Escola Politécnica, 1886 - 1889.

23. Escola Politécnica do Rio de Janeiro; Livro de atas da Congregação, 1884-1889.

24. Michler, W. \& Sampaio, A.; Revista de Engenharia (do Rio de Janeiro) 1883, 5, 119-121; 131-132 .

25. Rizzini, C. T. \& Mors, W. B.; Botânica Econômica Brasileira, São Paulo, EPU, 1976.

26. Revista de Engenharia (do Rio de Janeiro), 1884 - 1889.
27. Michler, W.; Revista Agrícola do Imperial Instituto Fluminense de Agricultura 1889, XX, 39-44.

28. Redondo, G. \& Theóphilo, R.; Botânica Elementar, Fortaleza, Fundação Waldemar Alcântara, Biblioteca Básica Cearense, 1997.

29. Michler, W.; Revista Agrícola do Imperial Instituto Fluminense de Agricultura, 1889, XX, 25-31.

30. Michler, W.; Revista Agrícola do Imperial Instituto Fluminense de Agricultura, 1889, XX, 31-36.

31. Michler, W.; Revista Agrícola do Imperial Instituto Fluminense de Agricultura, 1889, XX, 56.

32. Michler, W.; Revista Agrícola do Imperial Instituto Fluminense de Agricultura, 1885, XVI, 110.

33. Peckolt, T.; Catálogo explicativo da coleção enviada à Exposição nacional de 1866, 1866.

34. Tulloch, A P. \& Bergter, L.; Lipids 1976, 14, 996.

35. Michler, W.; Comemoração do $25^{\circ}$ aniversário do Instituto Politécnico Brasileiro, Rio de Janeiro, Tipografia Leuzinger \& filhos, 1887.

36. Lutz, W. R., Tese de concurso à vaga de lente substituto da única seção do curso de artes e manufaturas da Escola Politécnica, Rio de janeiro, Tipografia Leuzinger \& filhos, 1888. 